\title{
2 Transcultural and psychometric validation of the Dispositional 3 Resilience Scale (DRS-15) in Chinese adult women
}

\author{
4 Janet Yuen-Ha Wong • Daniel Yee-Tak Fong • Anna Wai-Man Choi • \\ 5 Claudia Kor-Yee Chan - Agnes Tiwari - Ko-Ling Chan • Vincent Lai • \\ 6 T. K. Logan · Paul Bartone
}

7 Accepted: 7 May 2014

8 (C) Springer International Publishing Switzerland 2014

\section{Abstract}

10 Purpose The aim of this study was to report translation 11 and transcultural adaptation of the 15-item Dispositional 12 Resilience Scale in traditional Chinese (C-DRS-15) and 1 AQ1 evaluate its psychometric properties.

14 Methods The DRS is a self-report instrument that measures 1 AQ2 psychological hardiness. We followed an international stan16 dard of cross-cultural translation and validation of patient17 reported outcome measures to create the Chinese version. 18 Then, the translated C-DRS- 15 was validated on 542 Chinese 19 women from a population-based sample in Hong Kong.

20 Results The internal consistency and criterion-related 21 validity were investigated. Exploratory and confirmatory 22 factor analysis revealed that the C-DRS-15 was supported by 23 a modified three-factor structure in our Chinese sample

$$
(\mathrm{RMSEA}=.06, \mathrm{CFI}=.94, \mathrm{TLI}=.92 \text {, and SRMR }=.06) \text {. }
$$

J. Y.-H. Wong $(\bowtie)$ - D. Y.-T. Fong · C. K.-Y. Chan - A. Tiwari A20 School of Nursing, Li Ka Shing Faculty of Medicine, The A21 University of Hong Kong, 4/F, William M.W. Mong Block, 21 A22 Sassoon Road, Pokfulam, Hong Kong, SAR e-mail: janetyh@hku.hk

D. Y.-T. Fong

e-mail: dytfong@hku.hk

C. K.-Y. Chan

e-mail: claudia2@hku.hk

A. Tiwari

e-mail: afytiwar@hku.hk

A. W.-M. Choi - K.-L. Chan

Department of Social Work and Social Administration, Faculty of Social Science, The Centennial Campus, The University of Hong Kong, Room 534, Jockey Club Tower, Pokfulam, Hong Kong, SAR

e-mail: annachoi@socwork.hku.hk

K.-L. Chan

e-mail: eklchan@hku.hk
The reliability (Cronbach's $\alpha$ coefficient $=.78$ ) and validity were satisfactory. Total resilience score was negatively correlated with depression $(p<.001)$, with non-depressed women scoring higher on the C-DRS- 15 .

Conclusions The C-DRS-15 was demonstrated to be a reliable and valid measurement to assess hardiness in Chinese women.

Keywords Psychometric validation - Hardiness ·

Resilience $\cdot$ Chinese $\cdot$ Psychological health

\section{Background}

Resilience research has emerged in social science and medical disciplines during the twenty-first century [1-3],
V. Lai

Department of Diagnostic Radiology, Li Ka Shing Faculty of Medicine, The University of Hong Kong, Room 406, Block K, Queen Mary Hospital, Pok Fu Lam Road, Pokfulam, Hong Kong, SAR

e-mail: laiv@hku.hk

\section{A26 T. K. Logan}

A27 Department of Behavioral Science, College of Medicine, A28 University of Kentucky, 333 Waller Avenue, Suite 480, A29 Lexington, KY 40504-2915, USA

A30 e-mail: tklogan@email.uky.edu

\section{A31 P. Bartone}

A32 A33 A34 A35
Center for Technology and National Security Policy (CTNSP), National Defense University, 300 5th Avenue SW, Washington, DC 20319, USA

e-mail: bartonep@gmail.com

\begin{tabular}{|c|c|c|c|c|}
\hline & Journal : Large 11136 & Dispatch & $15-5-2014$ & Pages: 6 \\
\hline & $\begin{array}{l}\text { Article No. : } 713 \\
\text { MS Code : } \quad \text { QURE-D-13-00948 }\end{array}$ & $\begin{array}{l}\square \boldsymbol{V E}_{\mathrm{CP}}^{\mathrm{LE}} \\
\boldsymbol{v}\end{array}$ & & $\begin{array}{l}\square \text { TYPESET } \\
\boldsymbol{\sim} \text { DISK }\end{array}$ \\
\hline
\end{tabular}


and resilience can promote positive mental health outcomes and psychological well-being [4]. The Dispositional Resilience Scale (DRS) is a measure of psychological hardiness, considered as a personality style to differentiate individuals under stress based on commitment towards life, control of life, and willingness to overcome challenges [5]. The original 45-item DRS scale was developed by Bartone [6], and later reduced to 30 and 15 items with satisfactory psychometric properties [7-9]. This study is to report the translation and transcultural adaptation of the 15-item DRS to traditional Chinese and evaluate its psychometric properties in a population-based sample of Chinese adult women in Hong Kong.

\section{Methods}

\section{Translation and transcultural adaptation}

Transcultural adaptation was consistent with the international standard of cross-cultural translation and validation of patient-reported outcome (PRO) measures (MAPI Institute: http://www.mapi-institute.com). The DRS-15 was translated by two native Chinese translators into the 15-item Dispositional Resilience Scale in traditional Chinese (C-DRS-15). The consensus version was translated back into English, and the two English versions were compared for consistency. The first C-DRS-15 was obtained after modification and refinements on semantic equivalence (same meaning with grammatical consideration), idiomatic equivalence (same expression), experiential equivalence (same application), and conceptual equivalence (validity of the concept) in the Chinese context [10]. Five Chinese adult women tested the first C-DRS-15, undergone cognitive debriefing via face-to-face interviews, and evaluated on completion time, length, relevance, clarity, and comfort of the instrument. Their comments were used for further item modification and refinements. The final C-DRS-15 was obtained thereafter and pre-tested on ten Chinese adult women to ensure administration feasibility to the public.

\section{Psychometric validation}

Two-stage systematic stratified sampling was applied on the data from a population-based household survey by the Census and Statistics Department in Hong Kong from April to August 2012. Addresses were first stratified according to geographical area by random sampling with fixed sampling intervals and non-repetitive random numbers. In the second stage, Chinese women aged 18 or older in each household residing in the selected stratum were randomly selected as respondents. Response rate was $68 \%(n=550)$. Non- participation encompassed both failure to contact potential respondents $(n=89)$ and refusals to respond $(n=164)$. Written consent was obtained from all respondents, and the study was approved by the University of Hong Kong/ Hospital Authority Hong Kong West Cluster Joint Institutional Review Board for both the cognitive debriefing (UW 12-047) and psychometric validation studies (UW 12-111).

The respondents anonymously answered the selfadministered questionnaire comprised of the C-DRS-15, the Chinese Edinburgh Depression Scale (C-EDS), and sociodemographics. The C-DRS-15 comprises 15 items covering three subscales: commitment, control, and challenge. All items are listed in Table 3 and rated on 4-point Likert scale $(0=$ not at all true, $1=$ slightly true, $2=$ quite true, 3 = completely true). The total score ranges from 0 to 45 , with a higher score representing greater psychological hardiness. The C-EDS measures depressive symptoms and comprises 10 questions rated on 4-point Likert scale, with total score ranging from 0 to 30 and cut-off score of $9 / 10$ recommended for Chinese [11]. Self-perceived resilience was assessed by yes-no question: "Do you think you are a person who can positively face difficulties and recover, learn, and grow from them?" Research assistant collected the completed questionnaires in a sealed envelope.

Construct validity of the C-DRS- 15 was examined by exploratory factor analysis (EFA) and confirmatory factor analysis (CFA) [12]. Prior to splitting the sample into the training and validation sets, two cases with more than $10 \%$ of missing data and six cases who were non-Chinese women were removed. In the training set $(n=261)$, we performed EFA with principal component extraction, scree plot assessment, geomin (oblique) rotation, and factor loadings examination. In the validation set $(n=281)$, CFA was used to assess the factor structure. The three-factor structure (commitment, control, and challenge) hypothesized in the original DRS was also assessed for its appropriateness in Chinese population. Internal consistency was assessed using Cronbach's $\alpha$ coefficient. Finally, convergent validity was examined by comparing the scores of depressed and nondepressed women with two-independent samples $t$ test and assessing the difference by the Cohen's $d$ effect sizes [15]. Depression was chosen for assessing convergent validity, because studies have reported that depressed women were less resilient than non-depressed women [4, 13, 14]. Data analysis was performed using Mplus 7.0 [16].

\section{Results}

The sample comprised 550 female participants. Almost all were Chinese ( $n=544,98.9 \%)$. Participants' characteristics are shown in Table 1. 
C-DRS-15 required refinement during the translation process, and participants commented that the items were relevant and they felt comfortable completing the questionnaire. The mean completion time of the scale was acceptable at $3.8 \mathrm{~min}$.

Table 2 shows the EFA factor loadings. The commitment factor comprised six items describing individual's vitality, strength, capacity, and promptness when facing hardship. The control-adaptation factor comprised six items of hardship resistance and coping, and difficulties with minimal changes. The positivity factor comprised three items describing individual's positive view of things and confidence in managing adverse events. The percentage of variance explained by each item on C-DRS-15 ranged from 31 to $81 \%$.

Table 1 Participant characteristics $(n=542)$

\begin{tabular}{lc}
\hline & $n(\%)$ \\
\hline Age (years) & \\
Under 20 & $63(11.6)$ \\
$20-29$ & $133(24.4)$ \\
$30-39$ & $108(19.9)$ \\
$40-49$ & $114(21.1)$ \\
50-59 & $70(12.8)$ \\
60 or over & $54(9.9)$ \\
Education & \\
None or below primary & $37(6.8)$ \\
Primary & $51(9.4)$ \\
Secondary & $324(59.6)$ \\
Tertiary or above & $131(24.1)$ \\
Employment status & \\
Employed & $229(42.1)$ \\
Housewives & $158(29)$ \\
Searching for jobs & $25(4.5)$ \\
Retired & $29(5.3)$ \\
Studying (full time) & $102(18.8)$ \\
Marital status & \\
Single & $22.82(6.2)$ \\
Married or cohabiting & \\
Separated/divorced/widowed & \\
Presence of chronic illness ${ }^{\mathrm{a}}$ in the past year & \\
Presence of financial difficulties in the past year & \\
Self-perceived hardiness by one yes-no question & \\
Chinese Dispositional Resilience Scale (C-DRS-15) & \\
total score (mean [SD]) & $286(52.4)$ \\
Edinburgh Depression Scale (EPDS) total score (mean & \\
[SD]) & \\
\hline
\end{tabular}

${ }^{a}$ Chronic illness refers to medical diagnosed diseases such as heart disease, hypertension, diabetes mellitus, asthma, chronic obstructive pulmonary disease, neurological diseases, headache, or chronic pain
The factor structure was assessed by CFA (Table 3). The originally hypothesized three-factor model (Model A) demonstrated unsatisfactory goodness of fit indices $(\mathrm{RMSEA}=.12, \mathrm{CFI}=.67, \mathrm{TLI}=.60$, and SRMR $=.09)$. After allowing for error covariances (Model B), the fit indices improved but remained unsatisfactory $(\mathrm{RMSEA}=.08$, $\mathrm{CFI}=.86, \mathrm{TLI}=.82$, and SRMR $=.07)$. The EFA-derived three-factor structure (Model C) with correlated error covariance had adequate goodness of fit (RMSEA $=.06$, $\mathrm{CFI}=.94, \mathrm{TLI}=.92$, and SRMR $=.06)$. The standardized estimates and path diagram of Model $\mathrm{C}$ are shown in Fig. 1.

Cronbach's $\alpha$ coefficient was .78 (commitment subscale, $\alpha=.78$; control-adaptation subscale, $\alpha=.75$; positivity subscale, $\alpha=.61$ ), which demonstrated moderate to high internal reliability [17]. Criterion-related validity was evident in the significant differences between the commitment score (depressed $8.78 \pm 3.6$; non-depressed $9.57 \pm 3.31$, $p=.02$ ), positivity score (depressed $5.34 \pm 1.96$; nondepressed $6.22 \pm 1.9, p<.001$ ), and total score (depressed $24.28 \pm 6.22$; non-depressed $26.47 \pm 5.81, p<.001)$. The Cohen's $d$ effect sizes for the commitment, positivity, and C-DRS-15 scales were small to moderate with a range from 0.23 to 0.46 . There was no significant difference in controladaptation score (depressed $10.14 \pm 3.47$; non-depressed $10.7 \pm 3.25, p=.07)$. In general, non-depressed women scored higher than depressed women on the C-DRS-15.

\section{Discussion}

This study revealed that the original three factors of the DRS-15 were not reproduced in our Chinese sample. Instead, C-DRS-15 with a modified three-factor structure of commitment, control adaptation, and positivity was valid and reliable. From a statistical perspective, the modified structure was developed with consideration of EFA results, goodness of fit statistics, and factor loadings during CFA. Marginal alpha coefficient for the positivity subscale (.61) was justified because of only three items. Furthermore, criterion-related validity was demonstrated with C-DRS-15 scores negatively correlated with depression.

From a theoretical perspective, the modified structure conveys meanings for Chinese women in our study. The commitment factor includes items from the original commitment, control, and challenge factors. Our findings imply that hardy Chinese women consciously integrate commitment, control, and challenge in devoting themselves to strategies to manage difficulties, solve problems, make decisions, and set goals while promptly deal with stressful events. The integration is consistent with the Chinese Connor-Davidson Resilience Scale [18] in Chinese individuals. Furthermore, Chinese take a holistic approach in 
Table 2 Factor loadings of the C-DRS-15 after geomin rotation $(n=261)$

\begin{tabular}{|c|c|c|c|c|}
\hline \multicolumn{2}{|l|}{ Items } & \multirow{2}{*}{$\begin{array}{l}\text { Commitment } \\
0.72\end{array}$} & \multirow{2}{*}{$\begin{array}{l}\text { Control adaptation } \\
0.03\end{array}$} & \multirow{2}{*}{$\begin{array}{l}\text { Positivity } \\
0.09\end{array}$} \\
\hline 1 & Most of my life gets spent doing things that are meaningful & & & \\
\hline 7 & I really look forward to my work activities & 0.50 & 0.30 & 0.08 \\
\hline 10 & Most days, life is really interesting and exciting for me & 0.66 & 0.05 & 0.09 \\
\hline 2 & By working hard you can nearly always achieve your goals & 0.82 & 0.05 & 0.04 \\
\hline 5 & Changes in routine are interesting to me & 0.47 & 0.06 & 0.33 \\
\hline 9 & I enjoy the challenge when I have to do more than one thing at a time & 0.46 & 0.01 & 0.29 \\
\hline 6 & How things go in my life depends on my own actions & 0.37 & 0.39 & 0.05 \\
\hline 12 & It is up to me to decide how the rest of my life will be & 0.21 & 0.53 & 0.11 \\
\hline 15 & My choices make a real difference in how things turn out in the end & 0.01 & 0.83 & 0.04 \\
\hline $3(\mathrm{R})$ & I don't like to make changes in my regular activities & 0.23 & 0.27 & 0.01 \\
\hline $11(\mathrm{R})$ & It bothers me when my daily routine gets interrupted & 0.05 & 0.42 & 0.03 \\
\hline $14(\mathrm{R})$ & I like having a daily schedule that doesn't change very much & 0.10 & 0.65 & 0.01 \\
\hline $4(\mathrm{R})$ & I feel that my life is somewhat empty of meaning & 0.02 & 0.03 & 0.71 \\
\hline $8(\mathrm{R})$ & I don't think there's much I can do to influence my own future & 0.15 & 0.01 & 0.57 \\
\hline $13(\mathrm{R})$ & Life in general is boring for me. & 0.09 & 0.16 & 0.60 \\
\hline \multicolumn{5}{|c|}{ Factor correlations } \\
\hline \multicolumn{5}{|c|}{ Commitment } \\
\hline \multicolumn{2}{|c|}{ Control adaptation } & 0.52 & 1.00 & \\
\hline \multicolumn{2}{|c|}{ Positivity } & 0.21 & 0.001 & 1.00 \\
\hline
\end{tabular}

Italic value indicates the highest factor loading of each item. The DRS-15 items are copyrighted material and may not be reproduced without permission. Information on use is available at www.kbmetrics.com

(R) indicates negatively keyed items

Table 3 Goodness of fit indices of different models $(n=281)$

\begin{tabular}{|c|c|c|c|c|c|c|}
\hline Models & $X^{2}$ & $d f$ & RMSEA & $\mathrm{CFI}$ & TLI & SRMR \\
\hline Model A (original three-factor model) & 428 & 87 & .12 & .67 & .60 & .09 \\
\hline Model B (original three-factor model with error covariance) & 221 & 80 & .08 & .86 & .82 & .07 \\
\hline Model C (EFA-derived three-factor model with error covariance) & 147 & 80 & .06 & .94 & .92 & .06 \\
\hline
\end{tabular}

RMSEA root-mean-square error of approximation, CFI comparative fit index, TLI Tucker-Lewis index, SRMR standardized root-mean-square residual

responding to daily demands [19], and this supports how commitment, control, and challenge cannot be isolated when hardy Chinese are dealing with stressful situations.

The control-adaptation factor contains items from the original control and challenge factors and reflects individual acceptance, suppression of changes, and restraint coping in the Chinese context. Chinese individuals believe in fate, with life events predetermined by external forces [20]. They perceive that individual efforts exert little influence on outcomes and prefer minimal changes when facing challenges since changes may tremendously affect the family. For Chinese women, "family harmony", "satisfying marriage", and "having blessed, well-behaved and high-achieving children" are significant values [21, 22]. Therefore, adaptation is the essence of managing stress and challenge in Chinese women.
The positivity factor serves as the cognitive resilient element in managing adverse events while reflecting peoples' positive expectations in life. These people are more optimistic and have confidence in overcoming problems and controlling their own future. Positive perceptions of adverse events and personal resources help in enhancing individual capability to deal with stressful circumstances $[23,24]$.

Despite our sample covered a wide spectrum of demographics in Hong Kong, study participants were Chinese women. Therefore, findings cannot be generalized to men. Also, data unavailability did not allow the examination of test-retest reliability, but such was reported high in DRS15 [9]. Finally, the study relied on self-reported data collected at one time point, so follow-up data would be of value in examining whether hardiness results are consistent

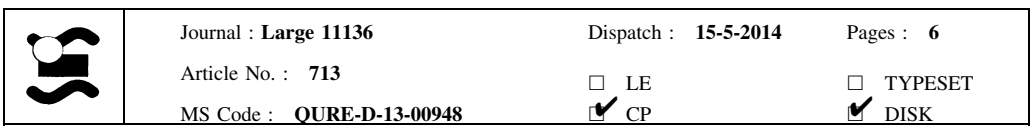




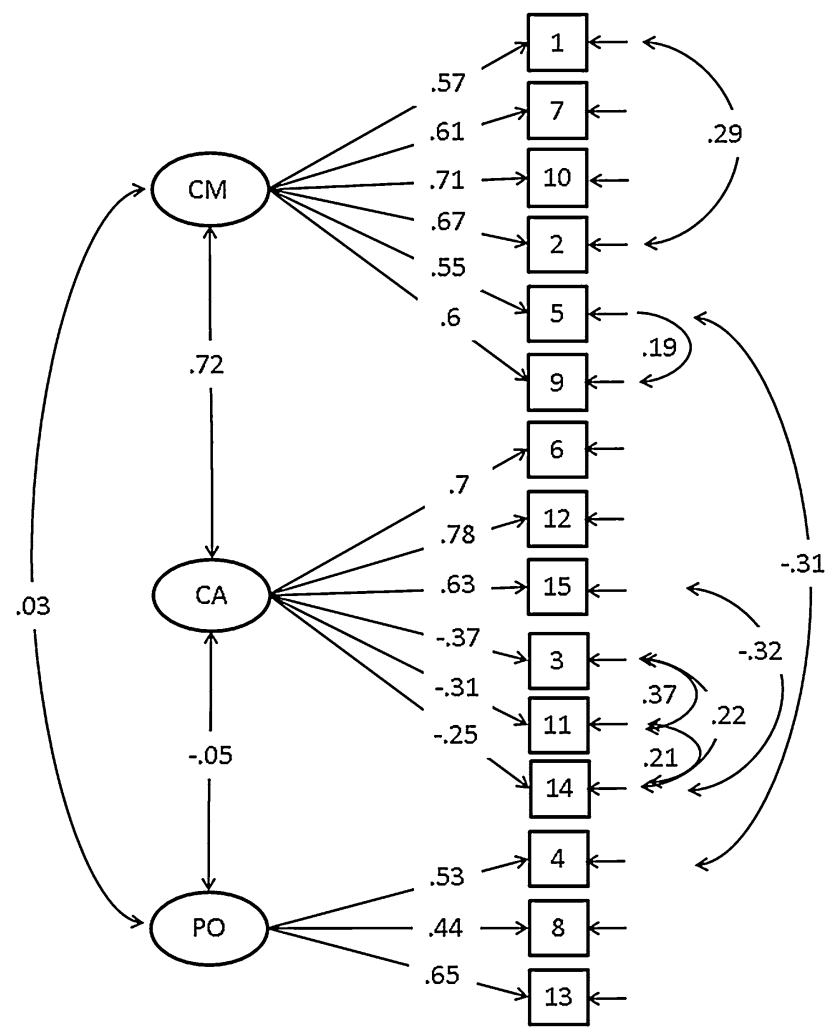

Fig. 1 Standardized estimates in a confirmatory factor analytic model of the C-DRS-15. $C M$ commitment, $C A$ control adaptation, $P O$ positivity

in demonstrating the dispositional traits of individuals in

Chinese society.

\section{Conclusions}

The present study is the first to confirm that the C-DRS-15, with modified factor structure from the original English DRS-15, is a reliable and valid measurement tool to evaluate hardiness in Chinese women.

Acknowledgments This study was financially supported by the Seed Funding Programme for Basic Research, the University of Hong Kong. We would also like to thank Ms. Ruby Tang for contributing to the manuscript editing.

Conflict of interest Paul Bartone receives royalties from the DRS15. The remaining authors declare that they have no competing interests.

\section{References}

1. Deegan, P. E. (2005). The importance of personal medicine: A qualitative study of resilience in people with psychiatric disabilities. Scandinavian Journal of Public Health, 33(66 suppl), 29-35.

2. Smith, B., Dalen, J., Wiggins, K., Tooley, E., Christopher, P., \& Bernard, J. (2008). The brief resilience scale: Assessing the ability to bounce back. International Journal of Behavioral Medicine, 15(3), 194-200.

3. Netuveli, G., Wiggins, R. D., Montgomery, S. M., Hildon, Z., \& Blane, D. (2008). Mental health and resilience at older ages: Bouncing back after adversity in the British household panel survey. Journal of Epidemiology and Community Health, 62(11), 987-991.

4. Davydov, D. M., Stewart, R., Ritchie, K., \& Chaudieu, I. (2010). Resilience and mental health. Clinical Psychology Review, 30(5), 479-495.

5. Kobasa, S. C. (1979). Stressful life events, personality, and health: An inquiry into hardiness. Journal of Personality and Social Psychology, 37(1), 1-11.

6. Bartone, P. T. (1989). Predictors of stress-related illness in city bus drivers. Journal of Occupational Medicine, 31(8), 657-663.

7. Bartone, P. T. (1995). A short hardiness scale. New York: The American Psychological Society Annual Convention.

8. Bartone, P. T. (1999). Hardiness protects against war-related stress in army reserve forces. Consulting Psychology Journal: Practice and Research, 51(2), 72-82.

9. Bartone, P. T. (2007). Test-retest reliability of the dispositional 20372 resilience scale-15, a brief hardiness scale. Psychological Reports, 101(3 Pt 1), 943-944.

10. Guillemin, F., Bombardier, C., \& Beaton, D. (1993). Cross-cultural adaptation of health-related quality of life measures: Literature review and proposed guidelines. Journal of Clinical Epidemiology, 46(12), 1417-1432.

11. Lee, D. T., Yip, S. K., Chiu, H. F., Leung, T. Y., Chan, K. P., Chau, I. O., et al. (1998). Detecting postnatal depression in Chinese women. Validation of the Chinese version of the Edinburgh Postnatal Depression Scale. The British Journal of Psychiatry, 172(5), 433-437.

12. Babyak, M. A., \& Green, S. B. (2010). Confirmatory factor analysis: An introduction for psychosomatic medicine researchers. Psychosomatic Medicine, 72(6), 587-597.

13. Southwick, S. M., Vythilingam, M., \& Charney, D. S. (2005). The psychobiology of depression and resilience to stress: Implications for prevention and treatment. Annual Review of Clinical Psychology, 1, 255-291.

14. Rodriguez, M. A., Heilemann, M. V., Fielder, E., Ang, A., Nevarez, F., \& Mangione, C. M. (2008). Intimate partner violence, depression, and PTSD among pregnant latina women. The Annals of Family Medicine, 6(1), 44-52.

15. Cohen, J. (1988). Statistical power analysis for the behavioral sciences (2nd ed.). Hillsdale: Lawrence Erlbaum Associates.

16. Muthén, L. K., \& Muthén, B. O. (2012). Mplus user's guide (7th ed.). Los Angeles: Muthén \& Muthén.

17. Moss, S., Patel, P., Prosser, H., Goldberg, D., Simpson, N., Rowe, S., et al. (1993). Psychiatric morbidity in older people with moderate and severe learning disability. I: Development and reliability of the patient interview (PAS-ADD). The British Journal of Psychiatry: The Journal of Mental Science, 163, $471-480$

18. Yu, X., \& Zhang, J. (2007). Factor analysis and psychometric evaluation of the Connor-Davidson Resilience Scale (CD-RISC) with Chinese people. Social Behavior and Personality: An International Journal, 35(1), 19-30.

19. Ji, L. J., Lee, A., \& Guo, T. (2010). The thinking styles of Chinese people. In M. H. Bond (Ed.), Oxford handbook of Chinese psychology. New York: Oxford University Press.

20. Leung, K., Bond, M. H., de Carrasquel, S. R., Munoz, C., Hernandez, M., Murakami, F., et al. (2002). Social axioms-The search for universal dimensions of general beliefs about how the world functions. Journal of Cross-Cultural Psychology, 33(3), 286-302.

21. Pearson, V., \& Leung, B. K. P. (1995). Women in Hong Kong. Hong Kong: Oxford University Press.

\begin{tabular}{|l|lll|}
\hline Journal : Large 11136 & Dispatch : $\mathbf{1 5 - 5 - 2 0 1 4}$ & Pages : $\mathbf{6}$ \\
Article No. : 713 & $\square$ LE & $\square$ TYPESET \\
& MS Code : QURE-D-13-00948 & $\checkmark$ CP & $\checkmark$ DISK \\
\hline
\end{tabular}


22. Kulich, S. J., \& Zhang, R. (2010). The multiple frames of 'Chinese' values: From tradition to modernity and beyond. In M. H. Bond (Ed.), Oxford handbook of Chinese psychology. New York, NY: Oxford University Press Inc.

23. Lazarus, R. S., \& Folkman, S. (1984). Stress, appraisal, and coping. New York: Springer.
24. Lazarus, R. S. (1993). Coping theory and research: Past, present, and future. Psychosomatic Medicine, 55(3), 234-247.

\begin{tabular}{|l|lll|}
\hline & Journal : Large 11136 & Dispatch : $\mathbf{1 5 - 5 - 2 0 1 4}$ & Pages : $\mathbf{6}$ \\
& Article No. : 713 & $\square$ LE & $\square$ TYPESET \\
& MS Code : QURE-D-13-00948 & $\sim_{\mathrm{CP}}$ & $\checkmark_{\text {DISK }}$ \\
\hline
\end{tabular}

